\title{
BMJ Open Effect of occupational safety and health education received during schooling on the incidence of workplace injuries in the first 2 years of occupational life: a prospective study
}

Stephanie Boini, Regis Colin, Michel Grzebyk

To cite: Boini S, Colin R, Grzebyk M. Effect of occupational safety and health education received during schooling on the incidence of workplace injuries in the first 2 years of occupational life: a prospective study. BMJ Open 2017;7:e015100. doi:10.1136/ bmjopen-2016-015100

- Prepublication history for this paper is available online. To view these files please visit the journal online (http://dx.doi org/10.1136/bmjopen-2016015100).

Received 9 November 2016 Revised 15 May 2017 Accepted 8 June 2017

CrossMark

Department of Occupational Epidemiology, INRS, Vandoeuvre-lès-Nancy, France

Correspondence to

Dr Stephanie Boini; stephanie. boini@inrs.fr

\section{ABSTRACT}

Objectives This study aimed to determine the effect of occupational safety and health (OSH) education during formal schooling on the incidence of workplace injuries (WIs) in young people starting their careers. We hypothesised that young people who had received OSH education during their schooling would have fewer Wls than those who received no OSH education. Secondary objectives focused on the effect of 'first aid at work' training during schooling and the conditions encountered on arrival in the company (occupational hazard information, safety training and job task training) on WI occurrence.

Design Prospective cohort study.

Participants From 2009 to 2012, French apprentices and students at the end of their schooling and starting their careers were included.

Outcomes Occurrence of Wis.

Methods At the time of inclusion, information about school courses and personal characteristics were collected, and subsequent half-yearly contacts gathered information relating to work and personal data. During the 2-year follow-up, Wls were directly reported by participants and were identified by searching the French National Health Insurance Funds' databases listing compulsory WI declarations.

Results 755 participants reported holding 1290 jobs. During follow-up, 158 Wls were identified, corresponding to an incident rate of 0.12 (0.10 to 0.14 ) Wls per full-time worker. Subjects who reported having received OSH education at school had two times less Wls than those declaring not having received $\mathrm{OSH}$ education (incidence rate ratio (IRR) 0.51 , 0.00 to 0.98 ). A lower WI risk was observed for participants who received the 'first aid at work' training ( $R R=0.68,0.00$ to 0.98 ). The conditions on arrival in company were not associated with Wls occurrence.

Conclusion In France, the OSH education provided to apprentices and students is mostly broader than the specific risks related to future jobs. Our results highlight the advantages of reinforcing this approach.

\section{INTRODUCTION}

Over the last 20 years, many studies have highlighted the fact that workplace injuries (WIs) in young people are sufficiently frequent

\section{Strengths and limitations of this study}

- Employment and working conditions are strong determinants of workplace injuries (WIs) in young people, but little is known about how occupational safety and health (OSH) education affects their occurrence. This study contributes to filling this gap.

- Assessments of OSH education at the time of inclusion and before the start of the job history, as well as the prospective follow-up of the population, are the major strengths of the study.

- Wis were assessed by participants during the followup and by matching the databases maintained by the National Health Insurance Funds' compensation system for Wls.

- Because of the observational design and the heterogeneity of the sample, stronger than expected frequency imbalances between groups were observed (in particular, 90\% of participants had received $\mathrm{OSH}$ education rather than the expected $70 \%)$.

to raise public health concerns in France, in Europe, in the USA and in Canada. ${ }^{1-6}$ In France, according to statistics generated by the workers' compensation system, in the age bracket of $<25$ years, 1 in 10 people are injured at work, while the annual frequency for all employee age groups is around 4 per 100 (corresponding to a rate of 23.5 WIs per million working hours in 2012). ${ }^{7}$

Several reviews of the literature relating to WIs among young people have been published. In 1995, Laflamme and $\mathrm{Menkel}^{8}$ in their review of studies published between 1977 and 1994 concluded that young people were more often injured than other employees, but that the injuries sustained were usually less severe. Salminen ${ }^{9}$ reviewed studies published between 1940 and 2000 and confirmed these observations, even if the results of the various studies were not entirely 
consistent. Breslin et $a l^{10}$ were interested in non-fatal WIs among non-agricultural workers under 25 years of age. They limited their scope to analytical studies published between 1997 and 2005. Because most published studies are descriptive, they only retained nine studies (among which six were cross-sectional) for their review. The results showed that the effects of gender and age on the incidence of WIs disappeared when factors related to work were taken into account. The effects of job type, activity sector, accumulation of occupational hazards or intense work seemed well established; however, the use of psychoactive substances, seniority, years of experience and whether work was supervised by a senior need to be further investigated. ${ }^{10}$

In line with these observations, prevention for young people has focused on providing occupational safety and health $(\mathrm{OSH})$ education. Thus, in Canada, for example, 75 prevention programmes were underway in $2005 .^{11} \mathrm{In}$ the USA, many approaches are focused on OSH for young and new employees. However, little quantitative information on how these approaches contribute to reducing WIs is available. ${ }^{12}$ In France, OSH education has been provided since 1993, thanks to a partnership between the French Ministry of Education and the National Health Insurance Funds. OSH skills are integrated into more than $80 \%$ of vocational education diplomas in the industrial and building trades, more than $50 \%$ of diplomas for service trades and in some 2-year technical degree diplomas in the administration and commerce sectors. However, how this specific preventive education during formal schooling contributes to reducing WIs has not yet been assessed.

The objective of this study was therefore to determine the effect of the OSH education received during schooling on the incidence of WIs in young workers at the start of their careers. We hypothesised that young people who had received OSH education during their schooling would have fewer WIs than those who received no OSH education. Secondary objectives focused on the effect of 'first aid at work' training during schooling and the conditions encountered on arrival in the company (occupational hazard information, safety training and job task training) on WIs occurrence, hypothesising that all these specific conditions could also contribute to reducing the incidence of WIs.

\section{STUDY POPULATION AND METHODS Study design}

This observational study was designed as a prospective cohort study, with a follow-up period of 2 years. Follow-up was based on responses to standardised questionnaires. The study population was composed of young people on the point of ending education to enter working life. The inclusion questionnaire was filled in by participants electronically or on paper, which assessed the educational courses (in particular in relation to OSH education, as the main factor of interest in this study), any work

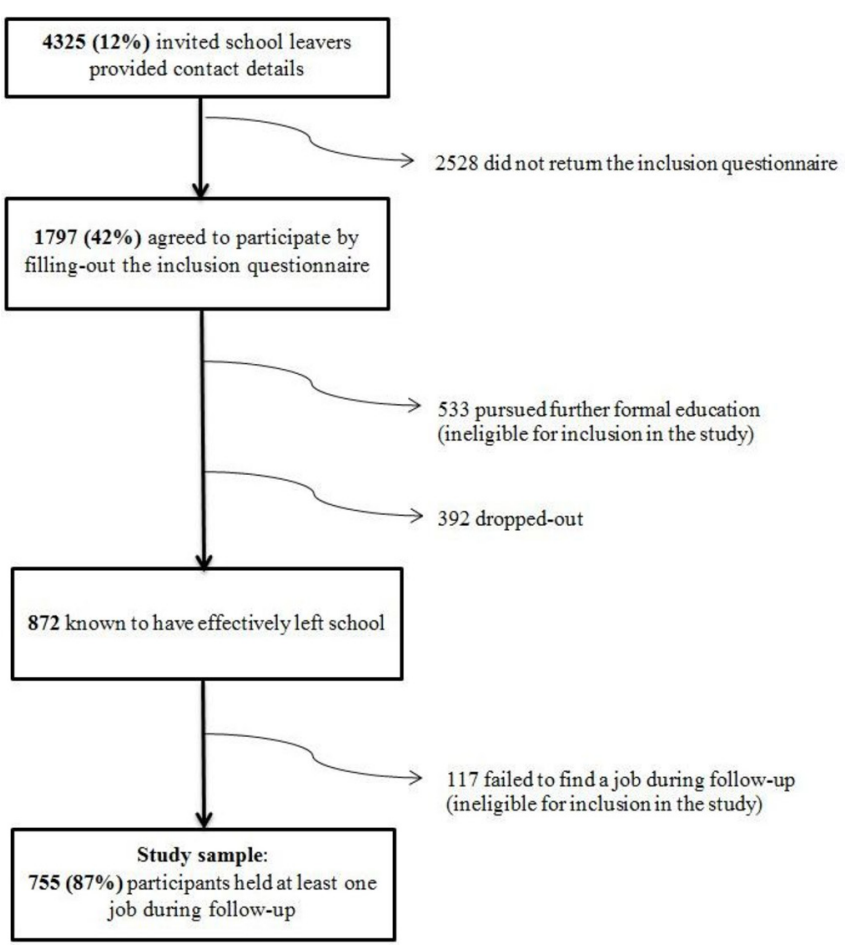

Figure 1 Flow chart illustrating selection of participants for inclusion.

experience gained during schooling and personal characteristics. The follow-up questionnaires, filled in every 6 months for a total of 2 years, were used to determine the incidence of WIs over the past 6 months, the characteristics of employment, the organisation of work and the working conditions, and the conditions encountered on arrival in the company.

The protocol was approved by the French National Committee for the Protection of Privacy and Civil Liberties (CNIL no 909103).

\section{Setting and participants}

During a 3-month period (March to May) each year from 2009 to 2012, information on the objectives and outline of the study was presented in 204 educational establishments providing vocational training all over France. The target population were apprentices , spending about $50 \%$ of their time at school and students with only limited internships in companies over the last year required to obtain their vocational educational diploma. To be eligible for inclusion, subjects had to have ended school and found a paid job-not necessarily related to their vocational training-during the 2years of the follow-up period: 755 participants met these criteria, and their data were further analysed (figure 1).

\section{Data collection}

Assessment of Wls

Participants declared WIs in their responses to questionnaires during the follow-up period. Participants were asked to supply the date and their job at the time of the 
WI. Information about any interruption of work due to the WI (at least 1 day off) was also recorded.

In parallel, outcomes were also measured, thanks to participant's social security IDs, which they communicated. These IDs were matched continuously with the databases maintained by the National Health Insurance Funds' compensation system for WIs. The data extracted contained information about WIs (almost the same information as provided by participants, plus the nature of injury).

\section{Main independent variable: OSH education}

Data relating to OSH education were gathered through the inclusion questionnaire. Participants were asked to provide information about any OSH education received during their school years (yes/no/don't remember), the content of this education and how it was provided.

Targeted OSH skills were (1) to identify the hazards related to work activity; (2) to alert to the presence of any hazardous situations; (3) to use available protective measures; (4) to behave appropriately in case of accident, incident or malfunction; (5) to assess the risks of injury or to health associated with the work situation; (6) to propose preventive measures that could be used to correct hazardous situations; (7) to eliminate or reduce occupational hazards from the stages of design of working situations; (8) to choose, validate and implement preventive measures. The number of target skills varied depending on the type of diploma.

\section{Factors related to educational courses}

Participants declared these factors at the time of inclusion. We collected information relating to the diploma to be obtained (certificat d'aptitude professionnell (CAP)/Brevet d'études professionnelles (BEP) certificates/vocational baccalaureate/brevet de technicien supérieur (BTS) certificates) and the educational scenario (apprenticeship/study). CAP/BEP certificates correspond to a national vocational qualification (level 353 of ISCED-2011), vocational baccalaureates correspond to a higher national vocational qualification (level 354 of ISCED-2011) and BTS certificates correspond to a short-cycle tertiary degree (level 554 of ISCED-2011). The specialisations of the diplomas prepared by participants were coded in line with the nomenclature of the specialty diplomas in the French national educational system and then categorised into production or service specialties. ${ }^{13}$

Participants were asked if the 'first-aid at work' training was provided (yes/no), which is an OSH-specific training, including core principles of OSH prevention. Finally, information about internship periods was gathered: total duration (weeks), completion of training/information on arrival, completion of availability of safety instructions/prevention modes and the number of injury(ies) incurred during school internship periods $(0 / 1 / 2 / 3$ or more).

\section{Factors related to work}

The factors related to the type of work were collected during the follow-up period. The job titles reported by participants were recorded according to the official French nomenclature ${ }^{14}$ and then categorised into service or production sector jobs. Participants were asked whether their job corresponded to their initial education (yes/ no), about the type of contract (permanent/fixed-term/ temporary/other), the weekly working hours ( 35 hours or more vs less than 35 hours/week) and the work schedules (day/night shift/day with more than a 2-hour break/ other). We also collected the size of the company based on the number of employees $(<10 / 10-49 / 50-199 />200)$ and the workplace (company premises/customers' premises/construction site/other).

We assessed the following workplace characteristics: multitasking (yes/no), multitasking only when necessary (yes/no), same working tasks as older colleagues (yes/ no) and exposure to work-related dangers (noisy environment, outdoor work, work in heat or cold conditions, work with chemicals, carrying of heavy loads, strained postures or vibration, repetitive movements, night work or shift work) (yes/no).

For each job, participants were asked whether information relating to occupational risks had been provided on their arrival (yes/no) and to indicate the time between receiving all this information and their arrival (in days), whether safety training was provided by the company (yes/no) and the time between completion of this safety training and arrival (in days), whether training for job tasks was provided by an experienced colleague (yes/no) and the number of days allocated for this training.

\section{Individual characteristics}

Participants declared these characteristics at the time of inclusion. Sociodemographic characteristics were related to age, gender and living conditions (live with parent(s), live with partner, live alone, others). Data concerning health and behavioural habits were as follows: perceived health status (very good/good/fair to bad), smoking status (yes/no), alcohol use (yes/no), cannabis use (yes/ no), regular sporting activity (yes/no), regular practise of leisure-time activities (yes/no) and previous injury(ies) incurred in daily life (yes/no). Finally, we assessed information about jobs held during school (temporary/ regular/holiday/casual).

\section{Statistical analyses}

All descriptive statistics are presented as means and SD for continuous variables and as absolute and relative frequencies for categorical variables. As the percentages of missing values do not exceed $5 \%$, relative frequencies for categorical variables were calculated without missing data.

Multiple Poisson regressions were performed using all WIs declared by participants or identified by searching the National Health Insurance Funds' compensation system databases as outcome $(\mathrm{n}=158)$, with a subject-specific 
random intercept, and the log of employment duration as offset. With this model, all other factors being equal, the incidence rate is constant and does not depend on the time since hiring. The parameters of this model can be interpreted as an incidence rate ratio (IRR).

The main factor of interest (OSH education) was included as an independent variable (yes vs no/don't remember), along with the relevant characteristics of the educational scenario (apprentice, specific 'first aid at work' training and correspondence between initial education and job) and the conditions encountered on arrival in the company (information provided on arrival about the occupational risks, safety training provided by the company and job task training from a more experienced colleague). The other factors collected in the questionnaires (ie, factors related to work and individual characteristics) were selected as independent factors for WIs, based on expertise (known effects from literature review) and statistical considerations. In the final model, factors associated with our outcome at the level of 0.20 were conserved: activity sector, work schedules, exposure to carrying heavy loads, strained postures or vibration, multitasking only when necessary, previous WIs during school internships, age, gender and cannabis use.

A multiple Poisson regression model displaying only WIs declared by the participants $(n=104)$ was used to analyse sensitivity of the results. All analyses were performed using Stata V.14.0.

The threshold for statistical significance was set to 0.05 . One-tailed tests were used to test the statistical significance for OSH education, the conditions encountered on arrival in the company (information on arrival about the occupational risks, safety training provided by the company, job task training by an older colleague) and training in 'first-aid at work', as we hypothesised that these conditions would help reduce WIs incidence. The other factors were assessed based on two-tailed tests to determine statistical significance.

\section{RESULTS}

\section{Inclusion process}

Among the 4325 potential participants contacted through the contact details they had provided, 1797 $(42 \%)$ confirmed their participation by returning the inclusion questionnaire (figure 1). The 2528 young who did not confirm their participation were more frequently women $(43.8 \%$ vs $30.3 \%)$, apprentices $(55.9 \%$ vs $60.4 \%)$, preparing a BTS certificate $(13.6 \%$ vs $7.4 \%)$ and preparing a specialty service diploma $(44.9 \%$ vs $35.2 \%)$. Among the 1797 confirmed participants, 650 were ineligible for inclusion-533 because they chose to pursue their schooling and 117 because they were unable to find a job during the 2-year follow-up period. Additionally, 392 (21.8\%) respondents to the initial questionnaire failed to complete any follow-up questionnaires (these were termed study dropouts); thus, the final study sample for analysis consisted of 755 individuals (figure 1).
Of the 755 study participants, 327 (43\%) gave their unique personal IDs for matching with the WIs databases. The comparison between data gathered from participants who transmitted their unique IDs and those who did not showed no differences with respect to age, gender, level of diploma, specialty of diploma, OSH education, cannabis use or perceived health status. The only difference was that apprentices more frequently gave their ID than other students ( $47 \%$ vs $38 \%)$.

\section{Characteristics of participants}

The characteristics of participants at the time of inclusion are presented in table 1 . Mean age was around 20 years. Nearly $70 \%$ of participants were living with their parent(s). Perceived health status was good, around 35\% were smokers, less than $10 \%$ were cannabis users and almost 25\% did not consume alcohol.

At the time of leaving school, more than $80 \%$ of participants graduated with their diploma. Nearly half the participants had prepared a vocational baccalaureate and $428(56 \%)$ were apprentices. About $90 \%$ of participants $(\mathrm{n}=687)$ reported having received OSH education as part of their initial schooling, and $60 \%$ had received specific training relating to first aid at work. During internship periods, training/information was provided on arrival for $62 \%$ of the cases, and safety instructions/prevention modes were available in $68 \%$ of cases. Around one-third reported having sustained one or more injury(ies) during internship periods (table 1).

Those who dropped out had the same initial characteristics as the participants overall, except they were more frequently smokers (52\% vs $37 \%$ ), had less frequently held jobs during their schooling (16\% vs $26 \%)$, were more frequently apprentices $(67 \%$ vs $57 \%)$ and were more frequently preparing a CAP/BEP certificate $(53 \%$ vs. $33 \%)$.

\section{Job characteristics}

During the 2-year follow-up period, participants reported having held 1290 jobs, corresponding to a mean of $1.7 \pm 1.0$ jobs per participant, with a maximum of 9 (table 2). These jobs covered a large variety of professions in production $(40.8 \%)$ or service industries $(59.2 \%)$. The most frequent jobs were salespeople/cashiers/self-service employees (16.5\%), construction workers (12\%), cooks/ multiskilled employees in restaurant services (8.7\%), handlers/packers $(5.6 \%)$ and hotel staff $(5.5 \%)$. Almost $70 \%$ of jobs were related to the diploma prepared. The conditions encountered on arrival in a company are summarised in table 2. Information about occupational hazards was provided one time in two, mostly by line managers or colleagues. Safety training was provided for fewer than $25 \%$ of jobs, whereas job task training from a more experienced colleague (senior) was provided in $70 \%$ of jobs.

\section{Workplace injuries}

Over the 2 years of follow-up, a total of 158 WIs were reported by participants or identified through the 
Table 1 Characteristics of participants and study dropouts at the time of inclusion

\section{Participants $(\mathbf{n}=\mathbf{7 5 5})$}

n

$\%^{*}$
Study dropouts $(\mathrm{n}=392)$

n

\section{EDUCATIONAL PARAMETERS}

Occupational Safety and Health education

\begin{tabular}{|c|c|c|c|c|}
\hline Yes & 687 & 91.4 & 359 & 93.7 \\
\hline No & 38 & 5.0 & 9 & 2.4 \\
\hline Don't remember & 27 & 3.6 & 15 & 3.9 \\
\hline \multicolumn{5}{|l|}{ Diploma } \\
\hline CAP/BEP certificates & 245 & 32.5 & 207 & 53.1 \\
\hline Vocational baccalaureate & 352 & 46.6 & 140 & 35.9 \\
\hline BTS certificate & 158 & 20.9 & 43 & 11.0 \\
\hline \multicolumn{5}{|l|}{ Diploma specialisation } \\
\hline Production & 405 & 53.6 & 227 & 58.1 \\
\hline Service & 350 & 46.4 & 164 & 41.9 \\
\hline Apprentice status & 428 & 56.7 & 260 & 66.5 \\
\hline $\begin{array}{l}\text { Received specific OSH training relating } \\
\text { to first aid at work }\end{array}$ & 450 & 60.0 & 243 & 63.1 \\
\hline $\begin{array}{l}\text { Total duration (weeks) of internship } \\
\text { periods, mean (SD) }\end{array}$ & 504 & $36.3(40.7)$ & 219 & $35.6(36.8)$ \\
\hline $\begin{array}{l}\% \text { completion of training/information at } \\
\text { start of internship periods, mean (SD) }\end{array}$ & 516 & $61.7(45.5)$ & 222 & $65.8(45.3)$ \\
\hline $\begin{array}{l}\% \text { completion of availability of safety } \\
\text { instructions/prevention modes during } \\
\text { internship periods, mean (SD) }\end{array}$ & 516 & $67.5(44.1)$ & 222 & $75.3(40.2)$ \\
\hline \multicolumn{5}{|l|}{$\begin{array}{l}\text { Number of workplace injury during } \\
\text { internship periods }\end{array}$} \\
\hline 0 & 483 & 65.0 & 229 & 60.3 \\
\hline 1 & 149 & 20.0 & 93 & 24.5 \\
\hline 2 & 57 & 7.7 & 32 & 8.4 \\
\hline 3 or more & 54 & 7.3 & 26 & 6.8 \\
\hline \multicolumn{5}{|l|}{ INDIVIDUAL CHARACTERISTICS } \\
\hline Male & 437 & 57.9 & 228 & 58.3 \\
\hline Age (years), mean (SD) & 754 & $20.5(2.7)$ & 391 & $19.7(1.9)$ \\
\hline \multicolumn{5}{|l|}{ Living conditions } \\
\hline Live with parent(s) & 521 & 69.3 & 285 & 73.8 \\
\hline Live with partner & 138 & 18.3 & 51 & 13.2 \\
\hline Live alone & 75 & 10.0 & 37 & 9.6 \\
\hline Others & 18 & 2.4 & 13 & 3.4 \\
\hline Smoker & 281 & 37.3 & 201 & 52.1 \\
\hline Cannabis use & 73 & 9.7 & 31 & 8.2 \\
\hline Alcohol use & 594 & 78.8 & 295 & 76.6 \\
\hline \multicolumn{5}{|l|}{ Perceived health status } \\
\hline Very good & 261 & 34.6 & 157 & 41.0 \\
\hline Good & 429 & 56.9 & 199 & 52.0 \\
\hline Fair/ bad/very bad & 64 & 8.6 & 27 & 7.0 \\
\hline Perform regular sporting activity & 316 & 42.7 & 166 & 43.5 \\
\hline
\end{tabular}


Table 1 Continued

\begin{tabular}{|c|c|c|c|c|}
\hline & \multicolumn{2}{|c|}{ Participants $(n=755)$} & \multicolumn{2}{|c|}{ Study dropouts $(\mathrm{n}=392)$} \\
\hline & $\mathbf{n}$ & $\% *$ & $\mathbf{n}$ & $\%$ * \\
\hline $\begin{array}{l}\text { Perform regular practise of leisure } \\
\text { activities }\end{array}$ & 364 & 50.7 & 164 & 44.1 \\
\hline $\begin{array}{l}\text { Sustained previous injury(ies) during } \\
\text { daily life: sport, road }\end{array}$ & 426 & 57.5 & 182 & 48.3 \\
\hline Regular & 44 & 23.7 & 16 & 27.6 \\
\hline Holiday & 120 & 64.5 & 30 & 51.7 \\
\hline Casual & 62 & 33.3 & 24 & 41.4 \\
\hline
\end{tabular}

*Percentages were calculated without missing data.

National Health Insurance Funds' databases. Seventy-seven $(49 \%)$ WIs were only declared by participants, $27(17 \%)$ WIs were both identified by participants and through the National Health Insurance Funds' databases and $54(34 \%)$ WIs were only identified through the National Health Insurance Funds' databases. Among these last 54 WIs, 43 WIs occurred after the last contact with the participants, but within follow-up period. The nature of the injury was not provided by participants (because they were not asked), but information from the National Health Insurance Funds' databases showed that, on the 69 injuries where the nature was known, injuries were mainly wounds and superficial injuries $(n=22,32 \%)$, external or internal trauma $(n=13,19 \%)$, sprains and strains $(n=6,9 \%)$ and traumatic shock $(n=5,7 \%)$.

The overall WI rate was $0.12(0.10$ to 0.14$)$ WIs per fulltime worker, corresponding to 64.9 (54.4 to 77.4) WIs per million of worked hours. One year after having left school, around $15 \%$ of participants had sustained an injury. The jobs most frequently associated with injury were construction worker $(n=28,19 \%)$, maintenance worker $(n=18$, $12 \%)$, cook/food service assistant $(n=18,12 \%)$ and butcher $(n=15,10 \%)$. Concerning the WIs declared by participants $(n=104), 65(63 \%)$ injuries required at least 1 day of sick leave $(11.5 \pm 10.5$ days $)$.

\section{Factors associated with the occurrence of WI}

The main result of the analysis presented in table 3 is that participants who reported having received $\mathrm{OSH}$ education at school had two times less WIs than those declaring not having received $\mathrm{OSH}$ education ( $\mathrm{IRR}=0.51$, 0.00 to 0.98 ), adjusted on relevant characteristics of education, the conditions on arrival in company and potential WI-related risk factors.

The conditions on arrival in a company were not linked to the occurrence of WIs. A decrease in the risk of WI was observed for participants who received the 'first aid at work' training (IRR=0.68, 0.00 to 0.98$)$. Other associations confirmed published observations: the lower risk of WIs in the services sector compared with the production sector (IRR=0.54, 0.31 to 0.94 ) and the higher risk of injury when exposed to physical strain (carrying heavy loads, strained postures or vibration) (IRR=2.25, 1.03 to 4.88 ) or night/shift work schedules (IRR=2.06, 1.07 to 3.97). Finally, difference between initial education and the job performed was not detected as a risk factor for WI (IRR=1.04, 0.61 to 1.78$)$.

Considering only WIs declared by participants as outcome in the multiple Poisson regression did not change the results overall. However, having received training in first aid at work (IRR=0.70, 0.00 to 1.04), working in services sector compared with production sector (IRR=0.63, 0.35 to 1.14 ) and being exposed to physical strain (IRR=1.64, 0.73 to 3.69 ) were no longer associated with the occurrence of WIs (not shown).

\section{DISCUSSION}

\section{Key results}

In this prospective follow-up study, among 755 young subjects in the first 2 years of working life after completion of their vocational education, 158 WIs were reported by participants or identified through the National Health Insurance Funds' databases. This corresponded to an overall WI rate of 0.12 (0.10 to 0.14$)$ WIs per full-time worker. Subjects who reported having received OSH education during schooling had two times fewer WIs than those having not received $\mathrm{OSH}$ education ( $\mathrm{IRR}=0.51$, 0.00 to 0.98 ) when analysed using a multiple Poisson regression. Our results thus suggest that OSH education during schooling helps protect against WI.

\section{Comparison to previously published data}

In 2013, the Working Conditions Survey allows to compare the participants of this study with all the employees of the same age (20-24 years) in continental France. ${ }^{15}$ The findings indicated that $42.6 \%, 56.6 \%$ and $16.8 \%$ of participants had to maintain painful or tiring postures for long periods, to wear or move heavy loads and to deal with vibrations, respectively. In our study, almost $80 \%$ of participants were exposed to one or more of these physical strains. In the earlier survey, $40 \%$ of employees 
Table 2 Employment characteristics of participants ( $n=1290$ jobs)

\begin{tabular}{|c|c|c|c|}
\hline & $\mathbf{n}$ & $\%^{*}$ & Mean (SD) \\
\hline \multicolumn{4}{|l|}{ JOB CHARACTERISTICS } \\
\hline Correspondence between initial education and job & 866 & 68.9 & \\
\hline \multicolumn{4}{|l|}{ Work sector } \\
\hline Production & 508 & 40.8 & \\
\hline Services & 737 & 59.2 & \\
\hline \multicolumn{4}{|l|}{ Work contract } \\
\hline Permanent & 447 & 35.6 & \\
\hline Fixed term & 562 & 44.7 & \\
\hline Temporary & 207 & 16.5 & \\
\hline Others & 40 & 3.2 & \\
\hline \multicolumn{4}{|l|}{ Size of company } \\
\hline$<10$ employees & 487 & 40.2 & \\
\hline $10-49$ & 351 & 29.0 & \\
\hline $50-199$ & 205 & 16.9 & \\
\hline $200-1000$ & 169 & 14.0 & \\
\hline Number of hours worked per week & 1204 & & $33.7(8.3)$ \\
\hline
\end{tabular}

Regular workplace

\begin{tabular}{|c|c|c|c|}
\hline Company premises & 981 & 80.4 & \\
\hline Customers' premises & 79 & 6.5 & \\
\hline Construction site & 119 & 9.7 & \\
\hline \multicolumn{4}{|l|}{ Work schedules } \\
\hline Regular & 374 & 31.3 & \\
\hline Shift/night & 251 & 17.6 & \\
\hline Others (morning, lunchtime, afternoon, flexible, etc) & 283 & 4.5 & \\
\hline Exposure to physical environment $†$ & 806 & 65.3 & \\
\hline Exposure to physical strain & 984 & 79.6 & \\
\hline Exposure to rhythms of work§ & 616 & 49.5 & \\
\hline Perform regularly multitasking & 396 & 32.4 & \\
\hline Information about occupational risks on arrival & 629 & 51.1 & \\
\hline From line management & 476 & 76.4 & \\
\hline From staff representatives & 215 & 34.5 & \\
\hline From occupational physician & 223 & 35.8 & \\
\hline From colleagues & 404 & 64.8 & \\
\hline From someone else & 58 & 9.3 & \\
\hline Time between provision of information and arrival (days) & 485 & & $17.8(66.3)$ \\
\hline Safety training provided by the company & 272 & 22.3 & \\
\hline Time between completion of training and arrival (days) & 221 & & $55.4(150.0)$ \\
\hline
\end{tabular}

*Percentages were calculated without missing data.

†Noisy environment, outdoor work, work in heat or cold, work with chemicals.

$\ddagger$ Carrying heavy loads, strained postures, vibration.

§Repetitive movements, night work, shift work. 
Table 3 Results of the multiple Poisson regression analysis of the number of workplace injuries

\begin{tabular}{|c|c|c|c|c|}
\hline & IRR & LCL & UCL & $\mathrm{p}$ value \\
\hline \multicolumn{5}{|l|}{ EDUCATIONAL PARAMETERS } \\
\hline Occupational safety and health education (yes vs no/don't remember) * & 0.51 & 0.00 & 0.98 & 0.04 \\
\hline Apprentice vs student & 0.76 & 0.46 & 1.25 & 0.29 \\
\hline First aid at work training (yes vs no) * & 0.68 & 0.00 & 0.98 & 0.04 \\
\hline Previous injury(ies) during school stage periods (yes vs no) & 2.46 & 1.56 & 3.90 & 0.000 \\
\hline Correspondence between initial education and job (yes vs no) & 1.04 & 0.61 & 1.78 & 0.88 \\
\hline \multicolumn{5}{|l|}{ JOB CHARACTERISTICS AND WORKPLACE CONDITIONS } \\
\hline Service sector vs production sector & 0.54 & 0.31 & 0.96 & 0.04 \\
\hline \multicolumn{5}{|l|}{ Work schedules (ref: regular) } \\
\hline Night/shift & 2.06 & 1.07 & 3.97 & 0.03 \\
\hline Daytime with more than 2 hours of break & 1.66 & 0.87 & 3.19 & 0.12 \\
\hline Others (morning, lunchtime, afternoon, flexible, etc) & 1.80 & 0.92 & 3.49 & 0.08 \\
\hline Physical strain exposure (yes vs no) $\dagger$ & 2.25 & 1.03 & 4.88 & 0.04 \\
\hline Multitasking only when necessary (yes vs no) & 1.18 & 0.73 & 1.90 & 0.49 \\
\hline \multicolumn{5}{|l|}{ CONDITIONS ON ARRIVAL IN COMPANY } \\
\hline Information about the occupational risks on arrival (yes vs no) * & 1.15 & 0.00 & 1.76 & 0.72 \\
\hline Safety training provided by the company (yes vs no) ${ }^{*}$ & 0.71 & 0.00 & 1.14 & 0.88 \\
\hline Job task training by an older colleague (yes vs no) * & 1.02 & 0.00 & 1.58 & 0.53 \\
\hline \multicolumn{5}{|l|}{ INDIVIDUALS CHARACTERISTICS } \\
\hline Age (years) & 0.85 & 0.75 & 0.96 & 0.009 \\
\hline Female vs male & 0.67 & 0.37 & 1.21 & 0.19 \\
\hline Cannabis use (yes vs no) & 2.12 & 0.98 & 4.56 & 0.06 \\
\hline
\end{tabular}

${ }^{*}$ One-tailed tests.

†Carrying heavy loads, strained postures, vibration.

IRR, adjusted incidence rate ratio; LCL, lower confidence limit; UCL, upper confidence limit.

aged 20-24 years reported having received information on occupational risks ( $51 \%$ in our study), and $28 \%$ were provided with safety training by their company $(22 \%$ in our study). The overall WI rates were comparable with our study, with $13.5 \%$ reporting at least one WI in the past 12 months compared with $15 \% 1$ year after entering into employment in our study.

In the literature, WIs in young people has been investigated in relation to two questions: (1) Which factors can explain the higher frequency of WI in young people compared with older workers? (2) Among young people, which factors are associated with the occurrence of WI? Most studies are descriptive, based on the records of compulsory declarations of WIs or self-reporting of WIs. Only a few longitudinal analytical studies have been performed. ${ }^{16}$ Thus, our study constitutes an interesting contribution.

The jobs undertaken by young people entering the labour market are not the same as the jobs occupied by an older population, and young people are therefore not exposed to the same occupational risks. Jobs held by young people are generally low skilled and perceived as physically more strenuous than jobs held by older workers. ${ }^{16}$ Our study, by design, did not address the question of the higher risk of WIs in the young compared with older workers, but the job characteristics indicated by participants corresponded to what is described in the literature. Indeed, $60 \%$ of jobs were in the services sector (in particular, salespeople, cashiers, self-service employees, multiskilled employees in restaurant services), mainly on fixed-term or temporary contracts $(61 \%)$, with atypical work schedules (24\% of working schedules were during the day but with breaks of more than 2 hours), and very frequently in companies with fewer than 50 employees $(70 \%)$.

Another literature review, focusing on the factors associated with the occurrence of WIs in young people, was conducted by Breslin et al in 2005. ${ }^{17}$ The main types of injuries reported in the 46 studies retained in this review were cuts, lacerations, needlestick injuries and sprains. These findings were confirmed in our study by the limited data extracted from the National Health Insurance Funds compensation system databases. Breslin et al concluded that sociodemographic factors (age and gender) and individual factors (personality traits) were not associated with the occurrence of WI. In contrast, factors related to employment (eg, industrial sector and work setting, specific occupational risks, perceived physical load) were 
considered to be risk factors for WI. ${ }^{17}$ For our study, we took the main risk factors for WI into consideration, as identified in the literature, ${ }^{101617}$ but our main focus was on the influence of OSH education. In their systematic review (22 studies published between 1997 and 2007), Robson $e t a l^{18}$ found strong evidence for an effect of training on workers' OSH behaviour, but insufficient evidence of its effectiveness on health outcomes. van Dijk $e t a l^{19}$ reviewed recent studies focusing on evaluation of OSH education. Of the 121 studies selected from those published in the previous 10 years, only 16 related to students (with much attention given to health disciplines) and none had WI as outcome. These authors underlined this disappointingly low number of evaluative studies and the need to improve the quality of studies. Our results indicated a protective effect of OSH education against the occurrence of WI. In France, OSH education and 'first aid at work' training are specifically targeted at vocational students or apprentices. Interestingly, discrepancies between initial education and job did not influence WI occurrence. This could be an indicator that there are advantages to maintaining a broad-spectrum education for both students and apprentices (no difference in WI incidence rate was observed between the two groups).

Young people are more vulnerable than older workers because of their lack of professional experience or different attitudes with regard to OSH. ${ }^{16}$ Schulte et al ${ }^{12}$ underlined the importance of a continuum of $\mathrm{OSH}$ education from school through to retirement. In our study, information about occupational risks was only provided on arrival in companies for $50 \%$ of the reported jobs, safety training was provided by the company in $22 \%$ of cases and job task training was provided by an older colleague in $70 \%$ of cases. Although we did not prove any significant association between these information/ training and the WI occurrence, a beneficial effect of OSH training methods on employee work practices has been reported elsewhere. ${ }^{18}{ }^{20}$ Intervention studies focusing on OSH strategies deployed on arrival in a company need to be developed.

\section{Strengths, limitations and generalisability}

Participants were recruited for this study between 2009 and 2012, in a situation of economic crisis that has affected France since 2008. This study was therefore carried out in a difficult context, made even more complex for the population targeted, who are more frequently affected by unemployment. Nonetheless, more than $70 \%$ of young people participated in the 2-year follow-up by filling in at least one questionnaire relating to their career pathway after leaving formal education, and more than $85 \%$ of them held at least one job over these 2 years. The incidence rate for WIs calculated in this study was 64.9 (54.4 to 77.4) injuries per million hours worked. The latest statistics published for young people indicated an incidence rate of 44.2 per million hours worked for young people aged 15-19 years and 27.8 per million hours worked for people aged $20-29$ years in $2010 .{ }^{21}$ The difference between the rates we report and these averages can be explained by the method of calculation and the nature of the WIs considered. The statistical values are based only on recognised WIs with loss of at least one working day and paid hours. For the rate reported here, we considered all WIs reported by young people and WIs identified through the National Health Insurance Funds' databases. Moreover, it is well known that WIs are under-reported to employers ${ }^{22}$ for economic reasons or to facilitate integration into the workplace. ${ }^{23}$

As with any observational study, results should be interpreted with caution when seeking to identify causality and biases (selection, memory and information) may have occurred. However, the assessment of OSH education at the time of inclusion and before the start of the job history and the prospective follow-up of our population are the major strengths of our study. These aspects lead to limited biases related to memory and information, which would be inherent to a retrospective assessment.

In contrast, selection bias may not have been avoided. Expected participation in a study targeting a general population is usually very low. For example, in the CONSTANCES cohort (age 18-69 years), ${ }^{24}$ the response rate was around $10 \%$; in the SUVIMAX cohort (35 years and older for women, 45 years and older for men), ${ }^{25}$ the response rate was about $15 \%$. Here, almost $12 \%$ of contact forms were returned, and about half of those that returned the contact form agreed to participate in the study. Given the target audience, this response rate is consistent with expectations. Among the study dropouts, some may have returned to school and some may not have found a job. Thus, only dropouts who had found a job contribute to the selection bias. The comparison of characteristics between participants and those who dropped out did not reveal any major differences, in particular with respect to $\mathrm{OSH}$ education. The participants were mostly men (56\%), had served apprenticeships (55\%) or had prepared a vocational baccalaureate (45\%). As previously underlined, the characteristics of the working conditions described by participants and the preventive measures used in the companies were quite comparable with those described by employees aged 20 to 24 years interviewed in the Working Conditions Survey in 2013. ${ }^{15}$

WIs were identified based on a double compilation: participants own declarations and results found by searching computerised databases compiled by the Regional Health Insurance Funds compensation system, using participants' social security numbers as unique IDs. Unfortunately, among the 755 participants, only $43 \%$ provided their unique ID. This low response clearly limited the number of WI, which could be identified from this source. The comparison between those who provided their personal ID and those who did not showed no marked differences.

Finally, because of the observational design and the heterogeneity of the sample, stronger than expected frequency imbalances between groups were observed (in particular, 90\% of participants had received $\mathrm{OSH}$ 
education rather than the expected $70 \%$ ), and some factors could therefore not be investigated in depth. For example, with respect to the conditions encountered on arrival in a company, the safety training provided by the company or the job task training by a colleague was considered as binary variables, instead of more detailed modalities, taking into account the time between completion and hiring date or the duration of training.

\section{CONCLUSION}

Few prospective analytical studies focusing on WIs in young people have been published. Results of this observational study indicate a decrease in the risk of WI for participants who had received OSH education during their schooling. In France, OSH skills are widely taught in vocational diplomas with a comprehensive approach (ie, wider than the specific risks related to the profession learnt). Our results suggest that there could be advantages to strengthening this approach.

Acknowledgements The authors are grateful to the members of the regional educational authorities and the educational institutions contacted who gave permission for implementation of the study and to the dedicated and conscientious participants in this study. They acknowledge Christine Bertrand, Monique Veille, Laurent Theveny and Aline Faget (Occupational and Health Safety Institute), Pascal Jacquetin and Stephanie de Flaugergues (Department of Occupational Risk Prevention from the National Health Insurance Funds), who helped during the study. Special thanks are expressed to Pascal Wild, who provided extensive comments on this work.

Contributors SB designed the study, oversaw data collection and validation, reviewed the literature, performed statistical analyses and drafted the manuscript. RC participated in study design, was instrumental in data collection and validation, and performed statistical analyses. MG participated in study design and performed statistical analyses. All authors collaborated interactively, read and approved the final manuscript.

Funding This research received no specific grant from any funding agency in the public, commercial or non-profit sectors.

Competing interests None declared.

Ethics approval French National Committee for the Protection of Privacy and Civil Liberties (CNIL no 909103).

Provenance and peer review Not commissioned; externally peer reviewed.

Data sharing statement № additional data are available.

Open Access This is an Open Access article distributed in accordance with the Creative Commons Attribution Non Commercial (CC BY-NC 4.0) license, which permits others to distribute, remix, adapt, build upon this work non-commercially, and license their derivative works on different terms, provided the original work is properly cited and the use is non-commercial. See: http://creativecommons.org/ licenses/by-nc/4.0/

(C) Article author(s) (or their employer(s) unless otherwise stated in the text of the article) 2017. All rights reserved. No commercial use is permitted unless otherwise expressly granted.

\section{REFERENCES}

1. Bhattacherjee A, Chau N, Sierra CO, et al. Relationships of job and some individual characteristics to occupational injuries in employed people: a community-based study. J Occup Health 2003;45:382-91.

2. Breslin $\mathrm{C}$, Koehoorn M, Smith $\mathrm{P}$, et al. Age related differences in work injuries and permanent impairment: a comparison of workers' compensation claims among adolescents, young adults, and adults. Occup Environ Med 2003;60:10e-10.

3. Cattledge GH, Schneiderman A, Stanevich R, et al. Nonfatal occupational fall injuries in the West Virginia construction industry. Accid Anal Prev 1996;28:655-63.

4. Chau N, Bourgkard E, Bhattacherjee A, et al. Associations of job, living conditions and lifestyle with occupational injury in working population: a population-based study. Int Arch Occup Environ Health 2008;81:379-89.

5. Khlat M, Ravaud JF, Brouard N, et al. Occupational disparities in accidents and roles of lifestyle factors and disabilities: a population-based study in north-eastern France. Public Health 2008;122:771-83.

6. McCall BP, Horwitz IB. Occupational vehicular accident claims: a workers' compensation analysis of Oregon truck drivers 1990-1997. Accid Anal Prev 2005;37:767-74.

7. Direction des Risques Professionnels - Mission Statistiques CNAMTS. [Summary tables of the French statistics of workplace injuries from the National Health Insurance Funds' compensation system - 2012]. 2013. http://www.risquesprofessionnels.ameli.fr/statistiqueset-analyse/sinistralite-atmp/dossier/syntheses-et-analysesstatistiques-de-la-sinistralite-par-ctn.html.

8. Laflamme L, Menckel E. Aging and occupational accidents a review of the literature of the last three decades. Saf Sci 1995;21:145-61.

9. Salminen S. Have young workers more injuries than older ones? An international literature review. J Safety Res 2004;35:513-21.

10. Breslin FC, Day D, Tompa E, et al. Non-agricultural work injuries among youth: a systematic review. Am J Prev Med 2007;32:151-62.

11. Breslin FC, Polzer J, MacEachen E, et al. Workplace injury or "part of the job"?: towards a gendered understanding of injuries and complaints among young workers. Soc Sci Med 2007;64:782-93.

12. Schulte PA, Stephenson $\mathrm{CM}$, Okun $\mathrm{AH}$, et al. Integrating occupational safety and health information into vocational and technical education and other workforce preparation programs. Am J Public Health 2005;95:404-11.

13. CNIS. Nomenclature des formations. 1994. http://www.insee.fr/fr/ themes/detail.asp?ref_id=ir-fqp03\&page=irweb/fqp03/dd/doc/nsf. $\mathrm{htm}$.

14. Direction de la recherche des études de l'évaluation et des statistiques. La nomenclature desfamilles professionnelles : Fap 2009. http://dares.travail-emploi.gouv.fr/dares-etudes-et-statistiques/ statistiques-de-a-a-z/article/la-nomenclature-des-famillesprofessionnelles-fap-2009.

15. Alvaga $E$, Vinck $L$. Contraintes physiques, prévention des risques at accidents du travail. Synthèse Stat 2015;10:140.

16. Health and Safety of Young Workers. Proceedings of a U.S. and Canadian Series of Symposia. National Institute for Occupational Safety and Health, 2013.

17. Breslin FC, Day D, Tompa E, et al. Systematic review of risk factors for work injury among youth. 93. Toronto: Institute for Work and Heath, 2005.

18. Robson LS, Stephenson CM, Schulte PA, et al. A systematic review of the effectiveness of occupational health and safety training. Scand $J$ Work Environ Health 2012;38:193-208.

19. van Dijk FJ, Bubas M, Smits PB. Evaluation studies on education in occupational safety and health: inspiration for developing economies. Ann Glob Health 2015;81:548-60.

20. Burke MJ, Sarpy SA, Smith-Crowe K, et al. Relative effectiveness of worker safety and health training methods. Am J Public Health 2006;96:315-24.

21. Direction de l'animation de la recherche des études et des statistiques. Les accidents du travail entre 2005 et 2010. Une fréquence en baisse. 10: Dares Analyses 2014;février.

22. Direction de l'animation de la recherche des études et des statistiques. Accidents, accidentés et organisation du travail. Résultats de l'enquête sur les conditions de travail de 1998. Premières synthèses 2002 20.1:10.

23. Daubas-Letourneux V. Connaissances des accidents du travail et parcours d'accidentés. Regard sociologique sur les angles morts d'une question de santé publique [Sociologie]. Faculté des Lettres et Sciences Humaines 2005.

24. Zins M, Goldberg M. CONSTANCES team. The French CONSTANCES population-based cohort: design, inclusion and follow-up. Eur J Epidemiol 2015;30:1317-28.

25. Hercberg S, Galan P, Preziosi P, et al. The SU.VI.MAX Study: a randomized, placebo-controlled trial of the health effects of antioxidant vitamins and minerals. Arch Intern Med 2004;164:2335-42. 